\title{
Genetic Analysis And Traits Association Study In Marker- Assisted Multi-Drought-Traits Pyramided Genotypes Under Reproductive-Stage Moisture Stress In Rice (Oryza Sativa L.)
}

Ashvinkumar Katral ( $\square$ ashokgkatral@gmail.com )

ICAR-Indian Agricultural Research Institute, New Delhi https://orcid.org/0000-0002-4000-0481

Hanamareddy Biradar

SPESS, Louisiana State University, Batan Rouge, LA 70803, United States

\section{Yallappa Harijan}

Central Sericultural Research and Training Institute Berhampore, West Bengal, India

Aruna Y. R.

University of Agricultural Sciences, GKVK, Bengaluru, India

Jagadeesh Hadimani

University of Agricultural Sciences, GKVK, Bengaluru, India

Shailaja Hittalmani

University of Agricultural Sciences, GKVK, Bengaluru, India

\section{Research Article}

Keywords: Drought, reproductive-stage drought stress, genetic variability, marker-assisted pyramiding, Lvene's test

Posted Date: September 21st, 2021

DOI: https://doi.org/10.21203/rs.3.rs-884435/v1

License: (c) (i) This work is licensed under a Creative Commons Attribution 4.0 International License. Read Full License

Version of Record: A version of this preprint was published at Euphytica on February 4th, 2022. See the published version at https://doi.org/10.1007/s10681-022-02974-5. 


\section{Abstract}

Reproductive-stage drought-stress is a major production constraint in rainfed rice ecosystem. Emergence of marker-assisted breeding strategies for developing drought-tolerant rice varieties are being optimized through exploiting adaptive-traits for their increased contribution towards grain-yield under recurring-drought. Grain-yield is a complex-trait; requires knowledge of genetics and association among yield contributing component-traits. Current study was undertaken using 21 marker-assisted multidrought-traits pyramided genotypes responses for genetic variability and association of traits for grain-yield under aerobic and reproductive-stage drought conditions. Field evaluation was carried-out in two seasons and data was collected on various parameters. Path-coefficient analysis was used as a selection criterion to select yield contributing-traits and found nine phenotypic traits were having a positive direct-effect on grain-yield during both and/or at least one season under both moistureregimes. The data from summer and Kharif seasons have been pooled within their respective moisture-regimes due to the nonsignificance of Levene's test of homogeneity of variances and estimated BLUP values. ANOVA based on BLUP values revealed significant differences for moisture-conditions and also among genotypes. Phenotypic variation via. box-plots and histogram depicted mean phenotypic differences of traits under two moisture-regimes. Majority of the traits possessed high PCV and GCV with high heritability and GAM indicating higher trait expression and additive gene action lead to effectiveness of selection under drought/moisture stress. Grain-yield possessed a positive correlation with all the component-traits under consideration during both moisture-regimes. Selection of genotypes based on these component-traits were rewarding and seems to be better selection-criteria. Finally, we can end-up with superior-genotypes suitable for intermittent-drought conditions.

\section{Introduction}

Grain production is the basis of global food security and is indispensable for feeding mankind worldwide; it needs a significant increase in output in the coming decades to sustain the food and feed requirements (Mesterhazy et al. 2020). As sustainability is the key factor in the production, globally rice, wheat, and maize are the three leading food crops; together they directly supply more than $50 \%$ of all calories consumed by the entire human population (FAO 2016). Among these, rice is a major cereal food crop in Asia and feeds more than two-third of a global population (Dowling et al. 1998; Fahad et al. 2019). Asia is the biggest producer and consumer of rice, accounting for $90 \%$ of the world's production and consumption (Khahani and Hittalmani 2015). About $55 \%$ of the rice area is irrigated and accounts for $75 \%$ of total rice production across the globe (Fahad et al. 2019). It signifies that rice is a water intensive crop and requires 5000 litres of water per kg rice grain production (Hittalmani 2010; Jana et al. 2018). Rice production is dwindling due to many abiotic and biotic factors (Korrens et al. 2017; Rawte et al. 2021). To meet the growing food demands of the population, it is critical to increase the productivity levels of rice by combating abiotic and biotic stresses (Roberts and Mattoo 2018).

Among the abiotic stresses, drought is the period of no rainfall or irrigation that affects plant growth and is a major production constraint for about $50 \%$ of the world production area of rice (Fahad et al. 2017). It is a major prevailing limiting factor affecting rice productivity in the Asian-Pacific region and reported to affect the area of 56 million hectares under different rice ecosystems (46 Mha: rainfed lowland and 10 Mha: rainfed upland) (Pandey et al. 2007; Bhandari et al. 2020). Varying intensities of drought stress at different developmental stages of crop via. seedling, vegetative and reproductive stages are quantified (Price and Courtois 1999; Tripathy et al. 2000; Nguyen and Bui 2008; Xu et al. 2011). In Asia itself, drought is reported to affect approximately 42 Mha of rice production (34 Mha: rainfed lowland and 8 Mha: rainfed upland) (Huke and Huke 1997). Drought causes more damage during reproductive stage moisture stress (RMS), especially during flowering stage (Venuprasad et al. 2007; Serraj et al. 2009) reducing the number of grains per panicle and increasing grain sterility; thereby reducing the grain yield of $34-53 \%$ under moderate stress and $65-88 \%$ under severe stress in comparison to irrigated condition (O'Toole 1982; Kumar et al. 2008; Torres and Henry 2018; Bhandari et al. 2020). Globally, rice production is predicted to be further challenged by an erratic and increasing frequency; even more severe drought due to climate change (Wassmann et al. 2009). Targeted higher productivity with climate resilience is thereby essential to stabilize rice production by creating climate-smart varieties for adverse ecologies.

The efforts are needed to address the problem of water scarcity by breeding new genotypes tolerance to moisture stress conditions. The alternate option is the growing of aerobic rice varieties, which can be grown in rainfed conditions (Hittalmani and Shivashankar 1987; Atlin et al. 2004; Zhao et al. 2010; Babu et al. 2011; Liu et al. 2019). Moreover, before taking any breeding 
programme, a breeder should have a thorough knowledge of nature and magnitude of genetic variability, heritability, genetic advance as per cent mean (GAM) and traits associations with grain yield in crop species under different moisture regimes (Lone et al. 2019). The multi-traits pyramided genotypes are thought to serve the problem of moisture stress conditions to a greater extent. Most of the economically important traits are complex and are the result of the interaction of a number of component traits. Understanding the relationship between grain yield and its component traits is most important step for making the best use of these relationships in selection. Grain yield is a complex trait; the direct selection of genotypes based on yield is misleading (Eltaher et al. 2021). Hence, the selection of genotypes suitable for reproductive stage moisture stress conditions based on component traits is most meaningful. The genotypes possessing higher genetic divergence would be responsible for improvement as they were likely to produce required recombinants upon crossing of such genotypes.

Breeding efforts at University of Agricultural Sciences, GKVK, Bengaluru has led to the development of set of $F_{9}$ generation marker-assisted multi-traits pyramided (MAP) lines with different combinations of gene/QTLs for drought tolerance, bacterial blight and blast disease resistance. However, these lines have not been characterised at phenotypic level under aerobic and reproductive stage drought stress. The present investigation was thus aimed to (i) assess the genetic variability among the MAP genotypes under aerobic and RMS conditions (ii) study the traits association for grain yield and related traits in MAP genotypes under aerobic and RMS conditions.

\section{Material And Methods}

\section{Plant material used and design of the experiment}

The present study comprised of $21 \mathrm{~F}_{9}$ generation marker assisted multi-traits pyramided genotypes obtained by crossing divergent parental lines 'RB6' (derived from cross RpBio $\times$ BL 122, resistant to leaf blast and bacterial blight diseases with fine grain quality) and 'QRT25' (derived from the cross IR64 × Azucena, drought-tolerant, high water use efficiency, high yielding with medium bold grain quality). The list containing the gene/QTLs possessed by the parents (RB6 and QRT25) have been presented in Table S1. $F_{1}$ plants were obtained and forwarded through marker assisted selection (MAS), genotypes were selected in each generation based on grain yield per plant (Haradari 2013; Uday 2016). Twenty-one marker assisted multi-traits pyramided genotypes along with the parents (RB6 and QRT25) and check (MAS 946-1) were evaluated for grain yield and other component traits under two moisture regimes namely aerobic (A) as control and reproductive stage moisture stress (RMS) as test environment during summer-2017 and Kharif-2017-18 seasons with two replications in randomized complete block design (RCBD) at experimental plots of Genetics and Plant Breeding, 'K' block, UAS, GKVK, Bengaluru.

\section{Reproductive stage moisture stress (RMS)}

The standard crop management practices were followed to grow the crop during both seasons. The crop management practices were the same till 75 days after sowing (DAS) in both moisture regimes. The water supply was withheld from 75 DAS in RMS condition to drain out available soil moisture and reproductive stage moisture stress was imposed at 80 DAS for the period of 15 days (Fig. 1) but in the aerobic condition, need based irrigation has been given throughout crop cycle in both the seasons (Fig. 1).

\section{Phenotypic evaluation}

The observations were recorded on five randomly selected plants from each marker assisted pyramided genotype in each replication from both aerobic and RMS conditions. Mean values were utilized for statistical analysis and the traits observed for eliciting the information are: plant height- $\mathrm{PH}(\mathrm{cm})$, days to $50 \%$ flowering- DFF, days to maturity- DM, productive tillers per plantPT, panicle length- PL (cm), panicle exertion- PE (cm), flag leaf length- FL (cm), spikelet fertility- SF (\%), 1000-grain weight- 1000GW (g), biomass yield- BM (kg/ha), harvest index- HI (\%) and grain yield- GY (kg/ha).

\section{Statistical analysis:}

Path analysis was carried out for both the season data (summer-2017 and Kharif-2017-18) and both moisture regimes (aerobic and RMS) separately via. Windostat v8.1 statistical software. Levene's test has been carried-out using SPSS v26 software to test 
the homogeneity of variances among summer and Kharif seasons data under two different moisture regimes. If the test is significant, the variances of both the season's differ significantly; if it is non-significant then both the season's variances are approximately equal or same. Hence, the decision on combining/pooling of data from both the seasons can be done. Due to non-significance of Levene's test, the summer and Kharif season data have been pooled within their respective moisture regimes and the Best Linear Unbiased Predictor (BLUP) values have been estimated via. Multi Environment Trail Analysis with R (METAR) statistical software. Further statistical analyses have been carried-out using BLUP values. BLUP-based analysis of variance (ANOVA) was done further to decide whether both the conditions (aerobic and RMS) data can be pooled or not and also to know statistical significance among the genotypes for various characters using Cropstat v7.2 statistical software. Phenotypic variation via. box plots, frequency distribution curves, estimation of genetic variability parameters [Phenotypic and Genotypic Coefficient of Variation (PCV and GCV), heritability $\left(\mathrm{h}^{2}\right)$ and genetic advance as percent mean (GAM)] and correlation plots have been deduced using 'R v4.1.0' statistical tool.

Formulae used for estimation of variability parameters are:

a. PCV and GCV were estimated as per Burton and Devane (1953)

$\operatorname{PCV}(\%)=\frac{\sqrt{\sigma 2_{P}}}{\bar{x}} \times 100$

$\mathrm{GCV}(\%)=\frac{\sqrt{\sigma 2_{G}}}{\bar{x}} \times 100$

b. Heritability in broad sense $\left(h^{2}(b)\right)$ was estimated as per Allard (1960)

$\mathrm{h}^{2}(\mathrm{bs})=\frac{\sigma 2_{G}}{\sigma 2_{P}} \times 100$

c. Genetic advance was estimated as per Johnson et al. (1955)

$\mathrm{GA}=\mathrm{Kh} \mathrm{h}^{2} \sigma \mathrm{p}$

Further, the GA as percent of mean (GAM) was estimated

$\mathrm{GAM}=\frac{G A}{\bar{X}} \times 100$

where, $\sigma 2 \mathrm{P}=$ Phenotypic variance, $\sigma 2 \mathrm{G}=$ Genotypic variance, $\overline{\mathrm{x}}=$ General mean of character, $\mathrm{K}=$ Selection differential at $5 \%(2.06)$ selection intensity, $\mathrm{h}^{2}=$ Broad sense heritability estimate, $\sigma p=$ Phenotypic standard deviation

\section{Results And Discussion}

Drought stress has emerged as an essential part of research and improvement of drought tolerance in plants is a thoughtprovoking task due to the complexity of these traits. Yield is one of the most important and complex trait; primarily affected by drought and leads to greater reduction in grain yield. It is both regulated by genes via. quantitative trait loci (QTLs) and even influenced by external environmental factors (Wang et al. 2012; Zeng et al. 2017). Selection of genotypes for prevailing environment solely based on yield is misleading. To overcome this complexity of decision, it is necessary to know association of traits for grain yield and it can act as strong evidence and most precise selection criteria.

\section{Path coefficient analysis as a selection criterion for growth and yield contributing traits:}

Path analysis was carried out for both the seasons' data under both the moisture regimes (Aerobic and RMS) separately for all the studied characters using phenotypic coefficient to ascertain the direct and indirect effect of the yield components on grain yield as suggested by Wright (1921) and Dewey and Lu (1959). Path analysis is a powerful tool to understand the association 
among different variables more clearly as recorded by simple correlation values by partitioning the overall association of particular variables with dependent variables into direct and indirect effects. The results of path coefficient analysis for studied traits under aerobic (A) and reproductive stage moisture stress (RMS) during summer-2017 (Table S2) and Kharif-2017-18 (Table S3) have been presented. Positive direct effect on grain yield was exhibited by productive tillers, biomass yield and harvest index under both moisture conditions during both the seasons. The similar results have been reported earlier by Venkataramana and Hittalmani 1999; Manickavelu et al. 2006; Uday 2016. Biomass yield has highest direct effect [summer $(A=0.632$ and RMS $=$ $0.579)$ and Kharif $(A=0.704$ and $R M S=0.778)$ ] followed by harvest index [summer $(A=0.348$ and $R M S=0.424)$ and Kharif $(A=$ 0.230 and RMS $=0.220)$ ]. The component traits like days to maturity $(A=0.009$ and $R M S=0.002)$ and productive tillers $(A=$ 0.031 and $R M S=0.068$ ) were contributing positively to grain yield during the summer season. The other traits like days to $50 \%$ flowering $(A=0.021 ; R M S=0.013)$, panicle exertion $(A=0.002 ; R M S=0.004)$, spikelet fertility $(A=0.009 ; R M S=0.015)$ and 1000 grain weight $(A=0.006 ; R M S=0.004)$ also contributing positive towards grain yield during Kharif season. The spikelet fertility $(A=-0.022 ; R M S=-0.063)$ has highest negative direct effect on grain yield and days to $50 \%$ flowering has lowest negative direct effect $(A=-0.009$; RMS $=-0.001)$ during summer season. Grain yield is a result of other component traits contributing directly or indirectly (Eltaher et al. 2021). The direct selection of genotypes based on component traits viz., harvest index and productive tillers can be adopted for enhancement of grain yield as they showed positive direct effect on grain yield (Khahani and Hittalmani, 2015). The lower residual effect under both moisture regimes during both the seasons [summer $(A=0.156 ; R M S=$ 0.199 ) and Kharif $=\mathrm{A}=0.102 ; \mathrm{RMS}=0.138)$ indicated that different characters other than the characters considered in this study influence the grain yield negligible.

By considering the positive contribution of component traits towards grain yield during both and/or either of the seasons under both the moisture regimes have been selected and further analysis have been carried out for these nine selected traits (viz., DFF, $\mathrm{DM}, \mathrm{PT}, \mathrm{PE}, \mathrm{SF}, 1000-\mathrm{GW}, \mathrm{BM}, \mathrm{HI}$ and GY) hereafter; mainly to focus on core contributing traits and to restrict our discussion to emphasise more on these traits.

\section{Levene's test of homogeneity of variances}

The results of Levene's test for selected traits have been presented in Table 1. Levene statistic in the table (1) represents F-test value at df1 and df2 degrees of freedom. Non-significance of Levene's statistic based on p-value $(>0.005)$ has been observed for all the phenotypic traits i.e., DFF, DM, PT, PE, SF, 1000-GW, BM, HI and GY across the seasons in both aerobic and RMS conditions separately. The positive sign of acceptance of Levene's homogeneity of variances, the trait variances of summer and Kharif seasons found to have equal variances in their respective moisture regimes (aerobic and RMS) (Levene 1960; O'Neill et al. 2002; Kim et al. 2018). Hence, the data from the summer and Kharif seasons have been pooled within their respective moisture regimes separately. 
Table 1

Levene's test of homogeneity of variances for yield and yield contributing traits under aerobic and reproductive stage moisture stress (RMS)

\begin{tabular}{|llllllllll|}
\hline Traits & Aerobic & & & & RMS & \\
\cline { 2 - 8 } & Levene statistic & df1 & df2 & p-value & Levene statistic & df1 & df2 & p-value \\
\hline DFF & 0.647 & 1 & 40 & 0.426 & 1.236 & 1 & 40 & 0.273 \\
\hline DM & 0.128 & 1 & 40 & 0.722 & 0.021 & 1 & 40 & 0.886 \\
\hline PT & 4.124 & 1 & 40 & 0.050 & 4.724 & 1 & 40 & 0.036 \\
\hline PE & 0.851 & 1 & 40 & 0.362 & 1.343 & 1 & 40 & 0.253 \\
\hline SF & 0.865 & 1 & 40 & 0.358 & 0.826 & 1 & 40 & 0.369 \\
\hline 1000-GW & 0.279 & 1 & 40 & 0.601 & 2.468 & 1 & 40 & 0.127 \\
\hline BM & 0.357 & 1 & 40 & 0.553 & 0.031 & 1 & 40 & 0.861 \\
\hline HI & 0.592 & 1 & 40 & 0.446 & 4.662 & 1 & 40 & 0.037 \\
\hline GY & 0.726 & 1 & 40 & 0.399 & 0.025 & 1 & 40 & 0.876 \\
\hline
\end{tabular}

d.f.- degrees of freedom, DFF- Days to $50 \%$ flowering, DM- Days to maturity, PT- Productive tillers plant ${ }^{-1}$, PE- Panicle exertion (cm), SF-Spikelet fertility (\%), 1000-GW- 1000-grain weight (g), BM- Biomass yield (kg/ha), HI-Harvest index (\%), GY- Grain yield (kg/ha)

\section{Estimation of BLUP value for pooled data}

BLUP, a standard method for estimating random effects of a mixed model (Robinson 1991);was used for estimating genetic merits. Due to the non-significance of Levene's test, the pooled data has been used to estimate combined BLUP values for all the phenotypic traits i.e., DFF, DM, PT, PE, SF, 1000-GW, BM, HI and GY under aerobic and RMS conditions separately (Table S3 and S4 respectively). The estimated BLUP values have been used for further analyses hereafter.

\section{ANOVA based on BLUP values for yield and yield attributing traits}

The results of ANOVA based on BLUP values under aerobic and RMS conditions revealed the existence of highly significant differences between aerobic and RMS conditions for all the phenotypic traits i.e., DF, DM, PT, PE, SF, 1000-GW, BM, HI and GY (Table 2). The prevailing moisture conditions for yield and yield attributes were adversely affected on the genotypic performance and indicating significant variability among the pyramided genotypes (Uaday 2016; Bhandari et al. 2020). The mean

performance among the genotypes varying significantly for all the traits deducing the presence of higher variability; the presence of variability is a pre-requisite factor for any plant breeding activity (Uday 2016; Bhandari et al. 2020; Harijan et al. 2021). Even the genotype $\times$ condition interaction also showed significant differences for the traits i.e., PT, PE, 1000-GW, HI and GY indicating the genotypic performance is better restricted to particular moisture condition (Uday 2016) (Table 2). Significant differences among the genotypes due to differential expression of gene/QTLs in MAP genotypes under aerobic and RMS conditions (Haradari 2013; Uaday 2016; Bhandari et al. 2020). Selection can be operated on available variability to select the suitable MAP genotype for prevailing/intermittent drought conditions; thereby achieving the sustainable production of grain yield under adverse climatic conditions. The significant results of BLUP-based ANOVA for the condition is strong evidence to conclude that the data on aerobic and RMS conditions have to be maintained separately and hence further analysis is carried-out individually for aerobic and RMS conditions. 
Table 2

BLUP-based analysis of variance (ANOVA) for yield and yield attributing traits

\begin{tabular}{|c|c|c|c|c|c|c|c|c|c|c|}
\hline \multirow{2}{*}{$\begin{array}{l}\text { Source of } \\
\text { variation }\end{array}$} & \multirow[t]{2}{*}{ d.f } & \multicolumn{9}{|c|}{ Mean sum of squares } \\
\hline & & DFF & $\mathrm{DM}$ & PT & $\mathrm{PE}$ & SF & $\begin{array}{l}1000- \\
\mathrm{GW}\end{array}$ & BM & $\mathrm{HI}$ & GY \\
\hline Replication & 1 & 8.68 & 9.33 & $0.54^{\star \star}$ & $7.90^{\star \star}$ & 1.65 & 0.75 & 635795 & $0.0038^{* *}$ & 2426.89 \\
\hline Condition & 1 & $16.30^{\star}$ & $131.25^{\star \star}$ & $87.61^{\star \star}$ & $18.37^{\star \star}$ & $595.24^{\star \star}$ & $18.52^{\star \star}$ & $97710000^{\star \star}$ & $0.039^{\star *}$ & $32670500^{* \star}$ \\
\hline Genotype & 20 & $51.85^{\star \star}$ & $95.73^{\star \star}$ & $12.84^{\star \star}$ & $14.90^{\star \star}$ & $173.95^{\star \star}$ & $13.59^{\star \star}$ & 6369000 & $0.0051^{\star \star}$ & $1476770^{\star \star}$ \\
\hline $\begin{array}{l}\text { Genotype } \\
\times \\
\text { Condition }\end{array}$ & 20 & 1.35 & 1.59 & $3.49^{\star *}$ & $1.54^{\star *}$ & 28.86 & $0.91^{\star \star}$ & 875283 & $0.0006^{* *}$ & $141167^{\star \star}$ \\
\hline Error & 41 & 3.80 & 8.67 & 0.092 & 0.70 & 23.33 & 0.20 & 4299050 & 0.0007 & 3462.12 \\
\hline Total & 83 & 14.99 & 29.43 & 5.04 & 4.62 & 67.59 & 3.83 & 5054130 & 0.0019 & 785224 \\
\hline \multicolumn{11}{|c|}{$*=$ significant at $5 \%$ level and $* \star=$ significant at $1 \%$ level, } \\
\hline
\end{tabular}

\section{Phenotypic variation of the traits among MAP genotypes under aerobic and RMS conditions}

Distribution of the measured phenotypic traits via. Box plots

Box-plots based on BLUP values for the phenotypic traits i.e., DF, DM, PT, PE, SF, 1000-GW, BM, HI, and GY presented in Fig. 2. The plots depicted the mean phenotypic differences under two moisture regimes (i.e., aerobic and RMS) and the performance of genotypes varied significantly except for days to $50 \%$ flowering and days to maturity (Fig. 2). Overall, the traits range was higher in aerobic compared to RMS; the traits PT, PE, 1000-GW, and GY exhibited symmetric distribution while the traits DF, DM, SF, BM, and $\mathrm{HI}$ exhibited skewed distributions under aerobic condition (Bhandari et al. 2020). Under RMS, all the traits values decreased in comparison to aerobic condition; the traits PT, 1000-GW and GY exhibited symmetric distribution under RMS also (Fig. 2). The mean consistent performance of genotypes under aerobic and RMS conditions is due to the presence of drought responsive gene/QTLs in the marker assisted pyramided genotypes (Haradari 2013; Uday 2016). The traits like PT, 1000-GW and GY distributed symmetrically under both moisture regimes can serve as strong selection criteria to select the genotypes for adverse conditions.

Distribution of the measured phenotypic traits via. histogram

Phenotypic traits variation via. histogram analysis among the MAP genotypes under aerobic and RMS conditions have been depicted separately using BLUP values and also represented the parental (RB6 and QRT25) and check MAS946-1 values in the histograms (Figs. 3 and 4). The frequency distributions for all the studied traits are found to be normal and following a standard normal distribution. The number of days required for flowering and maturity were found to be quite less as compared to parents (RB6 and QRT25) and check (MAS946-1) under both moisture regimes (Fig. 3and 4). The earliness in flowering and maturity is due to the recovery of transgressive segregants among the MAP genotypes (Haradari 2013). Earliness is one of the mechanism for drought escape and/or tolerance, hence these MAP genotypes can serve as a good source of breeding for adverse conditions (Haradari 2013; Uday 2016; Torres and Henry 2018). From among the parents and check, the mean performance of QRT25 is found to be better in aerobic as well as in RMS conditions since it is possessing higher mean values for the majority of the traits. Overall, the frequency distribution for all the traits is normal indicating to possess all kinds of combinations of gene/QTLs among the MAP genotypes (Haradari 2013). Hence, the histogram based selection of MAP genotypes for adverse conditions is additional support to the results of box plots. 


\section{Genetic variability parameters for yield and yield associated traits}

In any crop improvement programme, the availability of genetic variability is a first and foremost prerequisite (Venkataramana and Hittalmani 2003; Uday 2016; Bhandari et al. 2020; Harijan et al. 2021). The economically important characters like grain yield; a well-established complex character and influenced by the large number of genes that are greatly influenced by environmental factors. The genetic variability observed is the average of total hereditary effects of concerned genes as well as the environmental influence. Hence, the variability is partitioned into heritable and non-heritable components with suitable genetic variability components such as phenotypic coefficient of variation (PCV \%), genotypic coefficient of variation (GCV \%), heritability in a broad sense ( $\mathrm{h}^{2}$ bs \%) and genetic advance as per cent mean (GAM). The estimation of these variability parameters assists the breeder in achieving the projected crop improvement by operating selection on available variation.

In the current study, the genetic variability parameters viz., PCV, GCV, heritability and GAM for the phenotypic traits i.e., DF, DM, PT, PE, SF, 1000-GW, BM, HI and GY under both aerobic and RMS conditions have been presented in Table 3. Among all the studied characters, the highest PCV is observed than GCV; which indicated the role of environment on the expression of characters (Manjappa et al. 2014; Uday 2016; Harijan et al. 2021). The traits like productive tillers, panicle exertion, 1000-grain weight, biomass yield, harvest index and grain yield possessed high PCV and GCV with moderate to high heritability and high GAM under both moisture regimes. The spikelet fertility possessed moderate to high PCV and GCV with high heritability and GAM. This high heritability coupled with high GAM indicates that most likely the heritability is due to additive gene effects and the selection for aforesaid characters in drought/moisture stress conditions is found to be highly effective (Courtois et al. 2003; Singh and Narayan 2017). These traits are highly amenable for selection leading to high genetic variability and transmissibility while taking efforts towards crop improvement for grain yield under reproductive stage moisture stress condition (Singh et al. 2011; Haradari 2013; Manjappa et al. 2014).

Table 3

Estimates of components of genetic variability parameters for yield and yield attributing traits under aerobic and RMS conditions

\begin{tabular}{|c|c|c|c|c|c|c|c|c|}
\hline \multirow[t]{2}{*}{ Traits } & \multicolumn{2}{|l|}{ PCV \% } & \multicolumn{2}{|l|}{ GCV\% } & \multicolumn{2}{|l|}{$h^{2}$ bs (\%) } & \multicolumn{2}{|l|}{ GAM \% } \\
\hline & Aerobic & RMS & Aerobic & RMS & Aerobic & RMS & Aerobic & RMS \\
\hline DFF & 4.59 & 4.87 & 4.41 & 4.53 & 91.50 & 87.50 & 8.71 & 8.72 \\
\hline $\mathrm{DM}$ & 4.43 & 3.72 & 4.33 & 3.68 & 95.50 & 97.00 & 8.76 & 7.48 \\
\hline PT & 25.35 & 31.96 & 18.38 & 24.96 & 52.00 & 61.00 & 26.75 & 40.16 \\
\hline PE & 120.05 & 64.26 & 101.41 & 42.17 & 72.50 & 44.00 & 176.81 & 59.29 \\
\hline SF & 16.60 & 25.65 & 12.81 & 23.23 & 62.00 & 80.50 & 20.59 & 43.60 \\
\hline $1000-\mathrm{GW}$ & 20.05 & 26.72 & 14.03 & 24.73 & 50.50 & 83.00 & 20.56 & 47.26 \\
\hline BM & 31.19 & 37.59 & 22.14 & 26.90 & 51.50 & 53.00 & 32.60 & 40.41 \\
\hline $\mathrm{HI}$ & 22.47 & 31.89 & 15.55 & 22.40 & 50.00 & 51.00 & 22.36 & 32.49 \\
\hline GY & 36.48 & 46.77 & 25.20 & 35.74 & 47.00 & 57.50 & 35.89 & 56.26 \\
\hline
\end{tabular}

DFF- Days to $50 \%$ flowering, DM- Days to maturity, PT- Productive tillers plant ${ }^{-1}$, PE- Panicle exertion (cm), SF- Spikelet fertility (\%), 1000-GW- 1000-grain weight (g), BM- Biomass yield (kg/ha), HI-Harvest index (\%), GY-Grain yield (kg/ha)

\section{Association of yield and yield attributing traits under aerobic and RMS conditions among the MAP genotypes}

The correlation coefficient estimates the degree and direction of association between pair of characters and helps simultaneous improvement of the correlated traits through selection. The results of the correlation analysis have been depicted in Fig. 5a and 
$5 \mathrm{~b}$ under aerobic and RMS conditions respectively. Grain yield was possessing a positive correlation with all the phenotypic traits i.e., DF, DM, PT, PE, SF, 1000-GW, BM, and HI during both the moisture regimes except for 1000-GW in RMS condition. Similar results have been reported by Haradari 2013; Khahani and Hittalmani 2015; Uday 2016; Bhandari et al. 2020. The phenotypic trait 1000-GW is having a negative correlation with DF, DM, and PE under both moisture conditions (Fig. 5a and 5b). The existence of negative correlation among these traits is due to the prolonged period of flowering and maturity. Non-emergence of panicle from leaf sheath has an adverse effect on spikelet fertility, 1000-GW thereby on grain yield (Chakrabort and Chaturvedi 2014; Khahani and Hittalmani 2015). The selection of genotypes based on these component traits (DF, DM, PT, PE, SF, 1000-GW, $\mathrm{BM}$, and $\mathrm{HI}$ ) in addition to grain yield was rewarding; we can robust the selection criteria and end up with superior genotypes suitable for an adverse climatic condition to attain sustainability in production.

\section{Conclusions}

Drought is particularly damaging during the reproductive stage and reduces the grain yield drastically. Hence, the selection of genotypes solely based on grain yield is misleading. In our findings,path analysis identified nine phenotypic traits (days to $50 \%$ flowering, days to maturity, productive tillers, panicle exertion, spikelet fertility, 1000-grain weight, biomass yield, harvest index and grain yield), one can rely upon these traits to select drought tolerant genotypes under moisture stress conditions.. Nonsignificance of Levene's test of homogeneity of variances among the data from summer and Kharif seasons lead to data pooling within their respective moisture regimes and estimation of BLUP values. ANOVA based on BLUP values revealed significant differences for moisture conditions and genotypes for all the nine phenotypic traits. Phenotypic variation of traits via. box plots and histograms depicted the mean phenotypic differences for all the nine phenotypic traits among the MAP genotypes under both moisture regimes. The transgressive segregants have been observed among the MAP genotypes for early flowering and maturity. Majority of the traits possessed moderate to high GCV and PCV with moderate to high heritability and high GAM under both moisture regimes. Grain yield possessed a positive correlation with all the phenotypic traits under consideration. The selection based on these component traits is rewarding and we can end up with superior genotypes suitable for diverse climatic conditions to attain sustainability in production.

\section{Declarations}

\section{Conflict of Interest}

On behalf of all authors, the corresponding author states that there is no conflict of interest.

\section{Acknowledgement}

First author sincerely acknowledges Indian Council of Agricultural Research (ICAR) for providing Junior Research Fellowship (JRF) to pursue M.Sc. degree programme [File number: EDN/1/26/2015-Exam Cell].

\section{Authors' contribution}

Design of the experiment: AK and SH, Conduct of the experiments: AK, JH and AYR, Statistical analyses: YH and HB, Drafting of manuscript: $\mathrm{AK}, \mathrm{HB}$ and $\mathrm{SH}$

\section{Compliance with ethical standards}

This article does not contain any studies with human participants or animals performed by any of the authors.

\section{References}

1. Allard RW (1960) Principles of Plant Breeding. John Wiley and Sonc Inc., New York

2. Atlin GN, Laza M, Amante M, Lafitte HR (2004) Agronomic performance of tropical aerobic, irrigated, and traditional upland rice varieties in three hydrological environments at IRRI. The International Rice Research Insitute. DAPO 7777, Metro Manila, Philippines 
3. Babu N, Hittalmani S, Shivakumar N, Nandini C (2011) Effect of drought on yield potential and drought susceptibility index of promising aerobic rice (Oryza sativa L.) genotypes. Elect J Plant Breed 2:295-302

4. Bhandari A, Sandhu N, Bartholome J, Cao-Hamadoun TV, Ahmadi N, Kumari N, Kumar A (2020) Genome-wide association study for yield and yield related traits under reproductive stage drought in a diverse indica-aus rice panel. Rice 13:1-22. https://doi.org/10.1186/s12284-020-00406-3

5. Burton GW, Devane EH (1953) Estimation of heritability in tall festca (Festuca arundinacea) from replicated clonal materials. Agron J 45:478-481

6. Chakraborty S, Chaturvedi HP (2014) Genetic variability in upland rice (Oryza sativa L) genotypes of Nagaland. Indian Res J Genet Biotechnol 6:374-378

7. Courtois B, Shen L, Petalcorin W, Carandang S, Mauleon R, Li Z (2003) Locating QTLs controlling constitutive root traits in the rice population IAC 165× Co39. Euphytica. 134:335 - 45. https://doi.org/10.1023/B:EUPH.0000004987.88718.d6

8. Davierwala AP, Reddy APK, Lagu MD, Ranjekar PK, Gupta VS (2001) Marker assisted selection of bacterial blight resistance genes in rice. Biochem Genet 39:261-278. https://doi.org/10.1023/A:1010282732444

9. Dewey DR, LU KH (1959) A path analysis of crested grass seed production. Agron J 51:515-518

10. Dowling NG, Greenfield SM, Fisher KS (1998) Sustainability of rice in the global food system. International Rice Research Institute, Los Banos, p 404

11. Eltaher S, Baenziger PS, Belamkar V, Emara HA, Nower AA, Salem KF, Alqudah AM, Sallam A (2021) GWAS revealed effect of genotypex environment interactions for grain yield of Nebraska winter wheat. BMC Genom 22:1-4.

https://doi.org/10.1186/s12864-020-07308-0

12. Fahad S, Adnan M, Noor M, Arif M, Alam M, Khan IA, Ullah H, Wahid F, Mian IA, Jamal Y, Basir A (2019) Major constraints for global rice production. In: Advances in rice research for abiotic stress tolerance. Woodhead Publishing, Sawston. https://doi.org/10.2135/cropsci2006.03.0181

13. Fahad S, Bajwa AA, Nazir U, Anjum SA, Farooq A, Zohaib A, Sadia S, Nasim W, Adkins S, Saud S, Ihsan MZ (2017) Crop production under drought and heat stress: plant responses and management options. Front Plant Sci 29:8:1147. https://doi.org/10.3389/fpls.2017.01147

14. FAO (2016) Save and Grow in practice: maize, rice, wheat A guide to sustainable cereal production. ISBN 978-92-5-108519-6. pp. 120

15. Haradari C (2013) DNA marker assisted multiple trait QTL pyramiding for drought tolerant traits in rice (Oryza sativa L.). Ph. D. Thesis, Univ Agric Sci, Bengaluru, India

16. Harijan Y, Katral A, Mahadevaiah C, Biradar H, Hadimani J, Hittalmani S (2021) Genetic analysis of reciprocal differences for yield and yield attributing traits in segregating populations of rice (Oryza sativa L.). J Pharmacogn Phytochem 10:614-621

17. Hittalmani S (2010) Aerobic method of rice cultivation: Water saving and safe environment. Green farming: Green farming vision 2.1(5)

18. Hittalmani S, Shivashankar G (1987) Out crossing on male sterile lines of rice. Mysore J Agric Sci 21:158-160

19. Huke RE, Huke EH (1997) Rice area by type of culture: South, Southeast, and East Asia. International Rice Research Institute, Los Banos

20. Jana K, Karmakar R, Banerjee S, Sana M, Goswami S, Puste AM (2018) Aerobic rice cultivation system: eco-friendly and water saving technology under changed climate. Agr Sci Tech 13:1-5

21. Johnson HW, Robinson HF, Comstock RE (1955) Estimates of genetic and environmental variability in soybean. Agron J 47:314-318

22. Kahani F, Hittalmani S (2015) Genetic analysis and traits association in $F_{2}$ intervarietal populations in rice under aerobic condition. J Rice Res 3:152-157. doi:10.4172/2375-4338.1000152

23. Kim YJ, Cribbie RA (2018) ANOVA and the variance homogeneity assumption: Exploring a better gatekeeper. Br J Math Stat Psychol Brit J Math Stat Psy 71:1-2. https://doi.org/10.1111/bmsp.12103 
24. Korres NE, Norsworthy JK, Burgos R, Oosterhuis DM (2017) Temperature and drought impacts on rice production: An agronomic perspective regarding short and long term adaptation measures. Water Resou Rural Dev 9:12-27. https://doi.org/10.1016/j.wrr.2016.10.001

25. Kumar A, Bernier J, Verulkar S, Laffite HR, Atlin GN (2008) Breeding for drought tolerance: direct selection for yield, response to selection and use of drought- tolerant donors in upland and lowland-adapted populations. Field Crops Res 107:221-231. https://doi.org/10.1016/j.fcr.2008.02.007

26. Levene H (1960) Levene test for equality of variances. Contributions to probability and statistics. pp. $278-92$

27. Liu H, Zhan J, Hussain S, Nie L (2019) Grain yield and resource use efficiencies of upland and lowland rice cultivars under aerobic cultivation. Agronomy 9:591. doi:10.3390/agronomy9100591

28. Lone AA, Jumaa SH, Wijewardana C, Taduri S, Redona ED, Reddy KR (2019) Drought stress tolerance screening of elite American breeding rice genotypes using low-cost pre-fabricated mini-hoop modules. Agronomy 9:199. https://doi.org/10.3390/agronomy9040199

29. Manickavelu A, Nadarajan N, Ganesh SK, Gnanamalar RP, Babu RC (2006) Drought tolerance in rice: morphological and molecular genetic consideration. Plant Growth Regul 50:121-138. https://doi.org/10.1007/s10725-006-9109-3

30. Manjappa, Uday G, Shailaja H (2014) Association analysis of drought and yield related traits in $F_{2}$ population of Moroberekan/IR 64 rice cross under aerobic condition. Int J Agric Sci 4:79-88

31. Mesterhazy S, Olah J, Popp J (2020) Losses in the grain supply chain: Causes and solutions. Sustainability 12:2342. doi:10.3390/su12062342

32. Nguyen TL, Bui CB (2008) Fine mapping for drought tolerance in rice (Oryza sativa L.). Omonrice 16:9-15

33. O'Toole JC (1982) Adaptation of rice to drought prone environments. In: Drought resistance in crops with emphasis on rice. IRRI, Los Baños, pp 95-213

34. O'Neill ME, Mathews KL (2002) Levene tests of homogeneity of variance for general block and treatment designs. Biometrics 58:216-224

35. Pandey S, Bhandari H, Hardy B (2007) Economic costs of drought and rice farmers $\Downarrow$ coping mechanisms: a cross-country comparative analysis from Asia. International Rice Research Institute (IRRI), Los Banos, Philippines

36. Price AH, Courtois B (1999) Mapping QTLs associated with drought resistance in rice: progress, problems and prospects. Plant Growth Regul 29:123-133. https://doi.org/10.1023/A:1006255832479

37. Rawte S, Saxena RR, Verulkar SB (2021) Analysis of yield stability of rice (Oryza sativa L.) landraces under drought conditions with three different approaches. Indian J Genet 81:236-244

38. Roberts DP, Mattoo AK (2018) Sustainable agriculture-Enhancing environmental benefits, food nutritional quality and building crop resilience to abiotic and biotic stresses. Agric 8:8. https://doi.org/10.3390/agriculture8010008

39. Robinson GK (1991) That BLUP is a good thing: the estimation of random effects. Stat Sci 1:15-32

40. Serraj R, Kumar A, McNally KL, Slamet-Loedin I, Bruskiewich RM, Mauleon R, Cairns J, Hijmans RJ (2009) Improvement of drought resistance in rice. Adv Agron 103:41-98. https://doi.org/10.1016/S0065-2113(09)03002-8

41. Shen L, Courti B, Mcnally KL, Robin S, Li Z (2001) Evaluation on near isogenic lines of rice introgressed with QTL for root depth through marker aided selection. Theor Appl Genet 103:75-83

42. Singh P, Narayanam SS (2006) Biometrical techniques in plant breeding. Third revised edition. Kalyani Publishers, New Delhi

43. Singh SK, Singh CM, Lal GM (2011) Assessment of genetic variability for yield and its component characters in rice (Oryza sativa L.). Res Plant Biol 1:73-76

44. Steele KA, Price AH, Shashidhar HE, Witcombe JR (2006) Marker-assisted selection to introgress rice QTLs controlling root traits into an Indian upland rice variety. Theor Appl Genet 112:208-221. https://doi.org/10.1007/s00122-005-0110-4

45. Sun X, Yang Z, Wang S, Zhang Q (2001) Identification of a 47-kb DNA fragment containing Xa4, a locus for bacterial blight resistance in rice. Theor Appl Genet 106:683-687. https://doi.org/10.1007/s00122-002-1117-8

46. Torres RO, Henry A (2018) Yield stability of selected rice breeding lines and donors across conditions of mild to moderately severe drought stress. Field Crops Res 220:37-45. https://doi.org/10.1016/j.fcr.2016.09.011 
47. Tripathy JN, Zhang J, Robin S, Nguyen TT, Nguyen HT (2000) QTLs for cellmembrane stability mapped in rice (Oryza sativa L.) under drought stress. Theor Appl Genet 100:1197-1202

48. Uday G (2016) Evaluation of marker assisted introgressed multiple gene/QTL pyramided genotypes for abiotic and biotic stress in rice (Oryza sativa L.). Ph. D. Thesis, Univ Agric Sci, Bengaluru, India

49. Venkataramana P, Hittalmani S (1999) Genetic variability on some important traits in two $F_{2}$ segregants of rice (Oryza sativa L.). Crop Res 18:53-56

50. Venuprasad R, Lafitte HR, Atlin GN (2007) Response to direct selection for grain yield under drought stress in rice. Crop Sci 47:285-293. https://doi.org/10.2135/cropsci2006.03.0181

51. Wang Z, Cheng J, Chen Z, Huang J, Bao Y, Wang J, Zhang H (2012) Identification of QTL with main epistatic and QTLxenvironment interaction effects for salt tolerance in rice seedlings under different salinity conditions. Theor Appl Genet 125:807-815. https://doi.org/10.1007/s00122-012-1873-z

52. Wang ZX, Yamanouchi U, Katayose Y, Sasaki T, Yano M (2001) Expression of the Pib rice-blast-resistance gene family is upregulated by environmental conditions favouring infection and by chemical signals that trigger secondary plant defences. Plant Mol Biol 47:653-661

53. Wassmann R, Jagadish SVK, Sumfleth K, Pathak H, Howell G, Ismail A, Serraj R, Redona E, Singh RK, Heuer S (2009) Regional vulnerability of climate change impacts on Asian rice production and scope for adaptation. Adv Agron 102:91133. https://doi.org/10.1016/S0065-2113(09)01003-7

54. Wright S (1921) Correlation and causation. J Agric Res 20:557-585

55. Xu Q, Yuan XP, Yu HY, Wang YP, Tang SX, Wei X (2011) Mapping QTLs for drought tolerance at seedling stage in rice using doubled haploid population. Rice Sci 18(1):23-28. https://doi.org/10.1016/S1672-6308(11)60004-8

56. Yadav R, Courtois B, Huang N, McLaren G (1997) Mapping genes controlling root morphology and root distribution in a doubled haploid population of rice. Theor Appl Genet 94:619-632. https://doi.org/10.1007/s001220050459

57. Zeng D, Tian Z, Rao Y et al (2017) Rational design of high-yield and superior-quality rice. Nat Plants 3:17031. doi:10.1038/nplants.2017.31

58. Zhang J, Zheng HG, Aarti A, Pantuwan G, Nguyen TT, Tripathy JN (2001) Locating genomic regions associated with components of drought resistance in rice: comparative mapping within and across species. Theor Appl Genet 103:19-29

59. Zhao DL, Atlin GN, Amante M, Cruz MT, Kumar A (2010) Developing aerobic rice cultivars for water-short irrigated and drought-prone rainfed areas in the tropics. Crop Sci 50:2268-2276. https://doi.org/10.2135/cropsci2010.10.0028

\section{Figures}



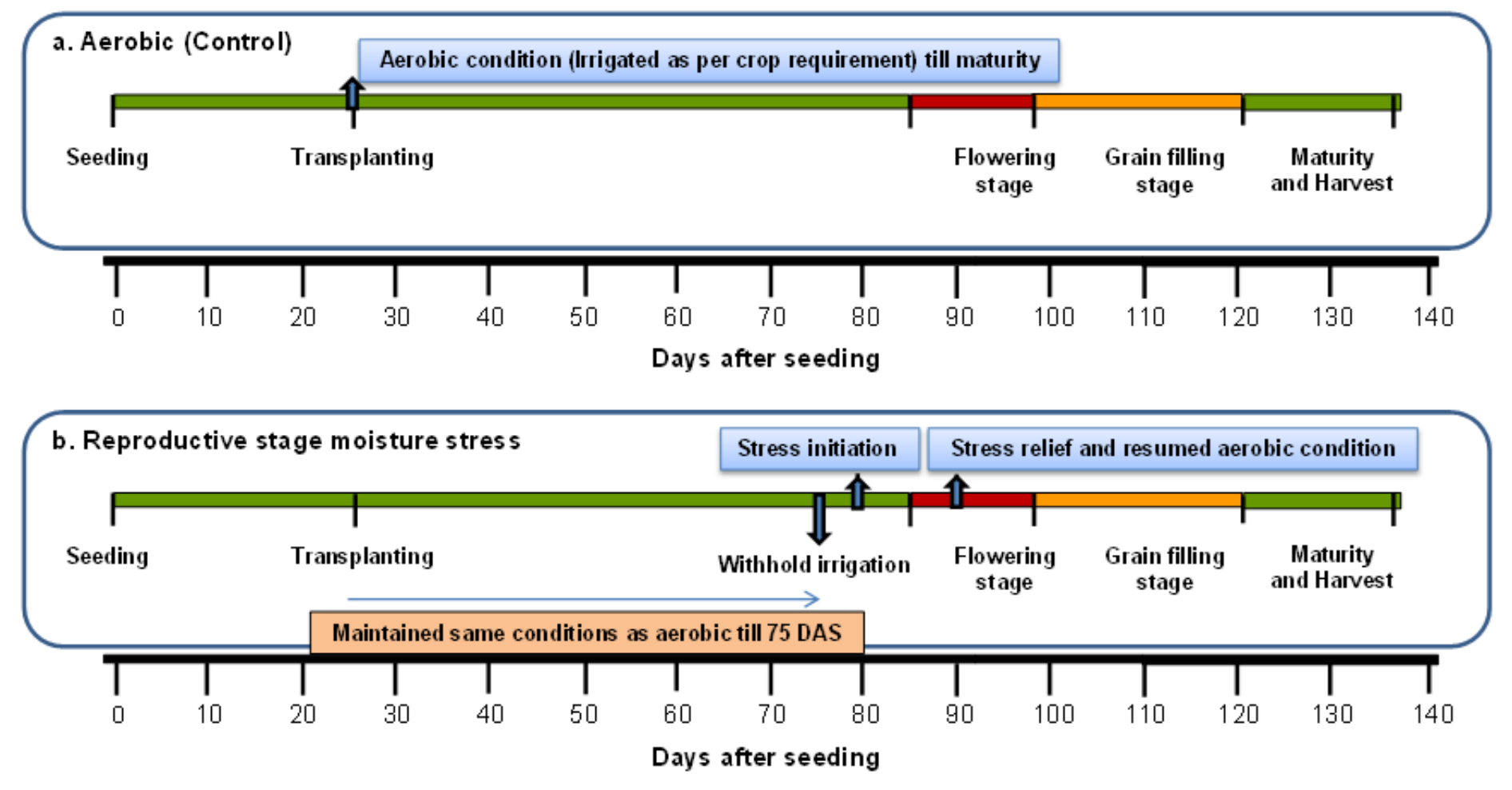

Figure 1

Protocol to impose moisture stress; a. Aerobic as normal, b. Reproductive moisture stress (RMS) as stress environment

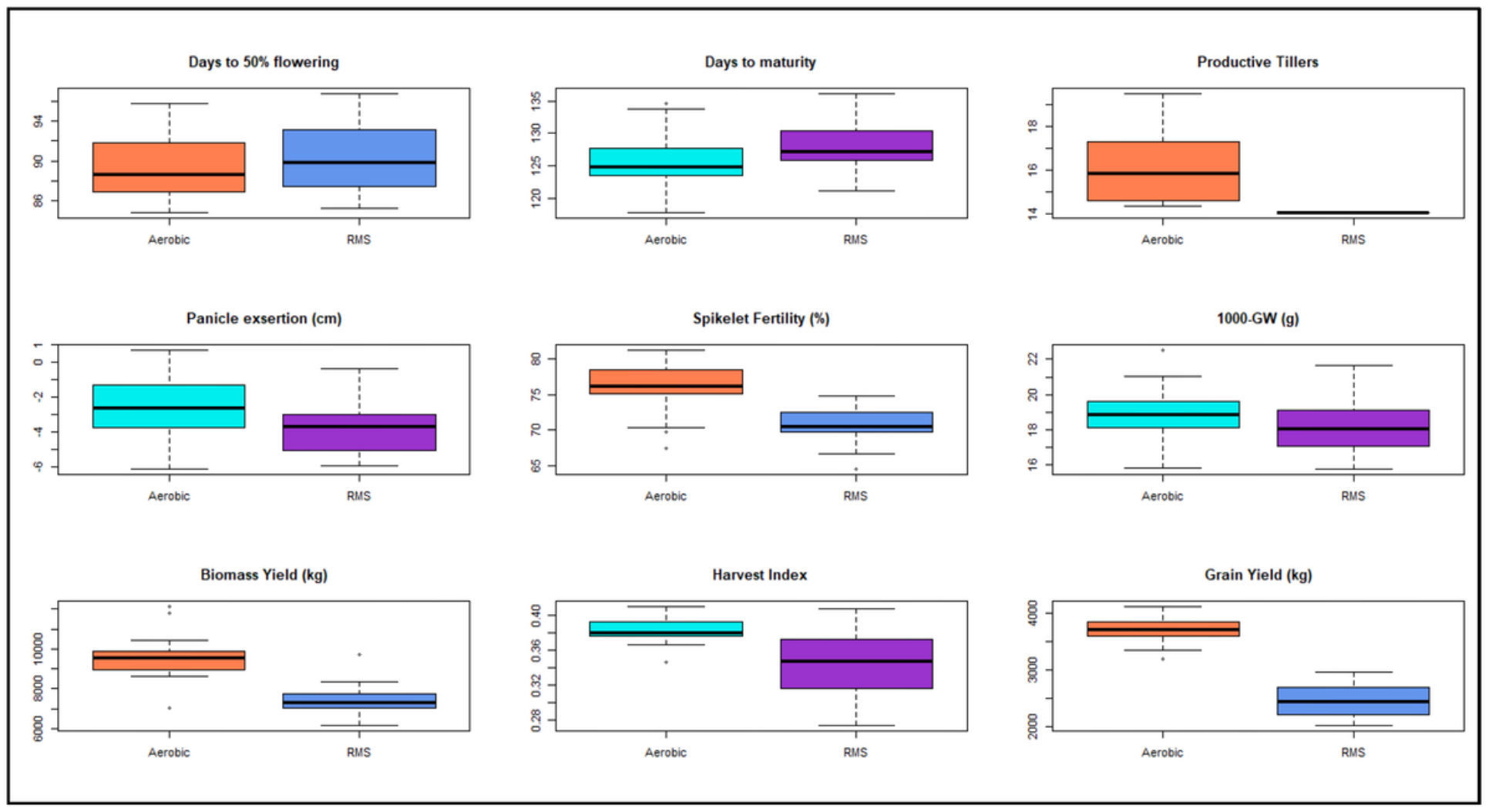

Figure 2

Boxplots of nine phenotypic variables within MAP genotypes under aerobic and RMS conditions; Days to 50\% flowering, Days to maturity, Productive tillers per plant, Panicle exertion (cm), Spikelet fertility (\%), 1000-grain weight (g), Biomass yield (kg/ha), 
Harvest index and Grain yield ( $\mathrm{kg} / \mathrm{ha})$. The boxplots are divided into aerobic and RMS for each trait. Within the boxplots, bold line represents the median, box edges represent upper and lower quantiles, and whiskers are 1.5 times the quantile of the data. Open dots represent the outliers
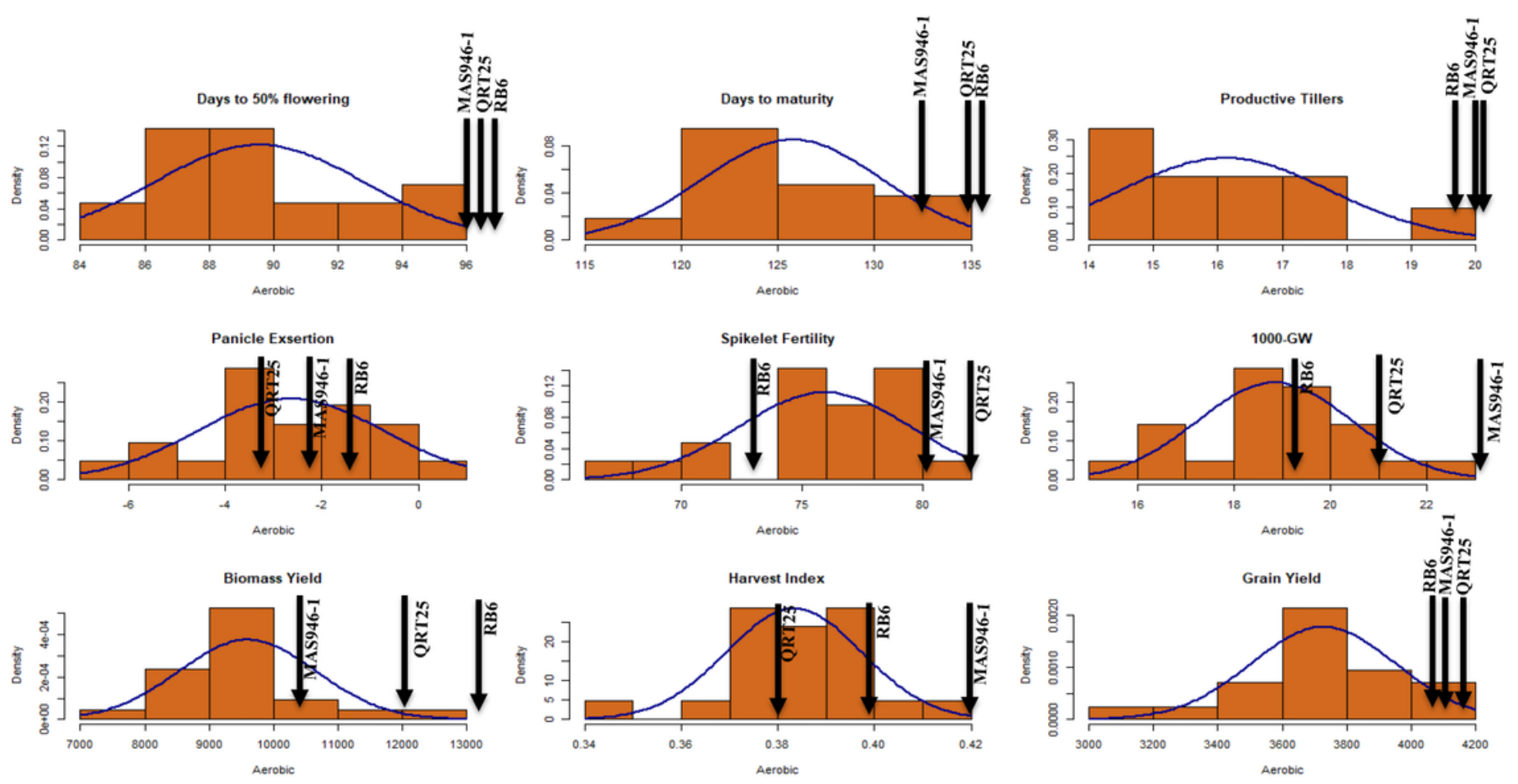

\section{Figure 3}

Frequency distribution plots of nine phenotypic variables within MAP genotypes under aerobic condition; Days to 50\% flowering, Days to maturity, Productive tillers per plant, Panicle exertion (cm), Spikelet fertility (\%), 1000-grain weight (g), Biomass yield (kg/ha), Harvest index and Grain yield(kg/ha). RB6 and QRT25 are the parents of the MAP genotypes and MAS946-1 is used as check. 

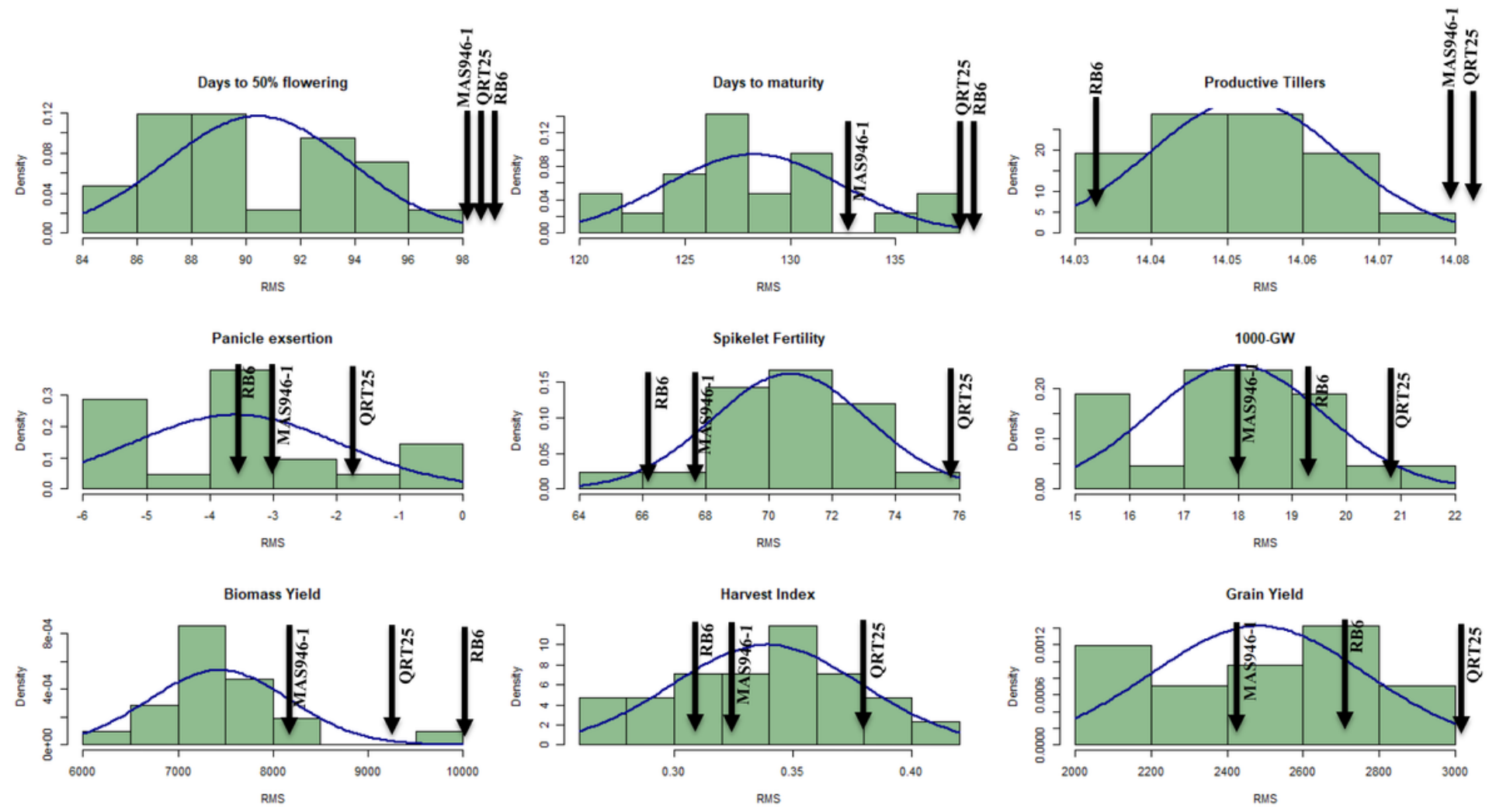

\section{Figure 4}

Frequency distribution plots of nine phenotypic variables within MAP genotypes under RMS condition; Days to $50 \%$ flowering, Days to maturity, Productive tillers per plant, Panicle exertion (cm), Spikelet fertility (\%), 1000-grain weight (g), Biomass yield (kg/ha), Harvest index and Grain yield (kg/ha). RB6 and QRT25 are the parents of the MAP genotypes and MAS946-1 is used as check. 


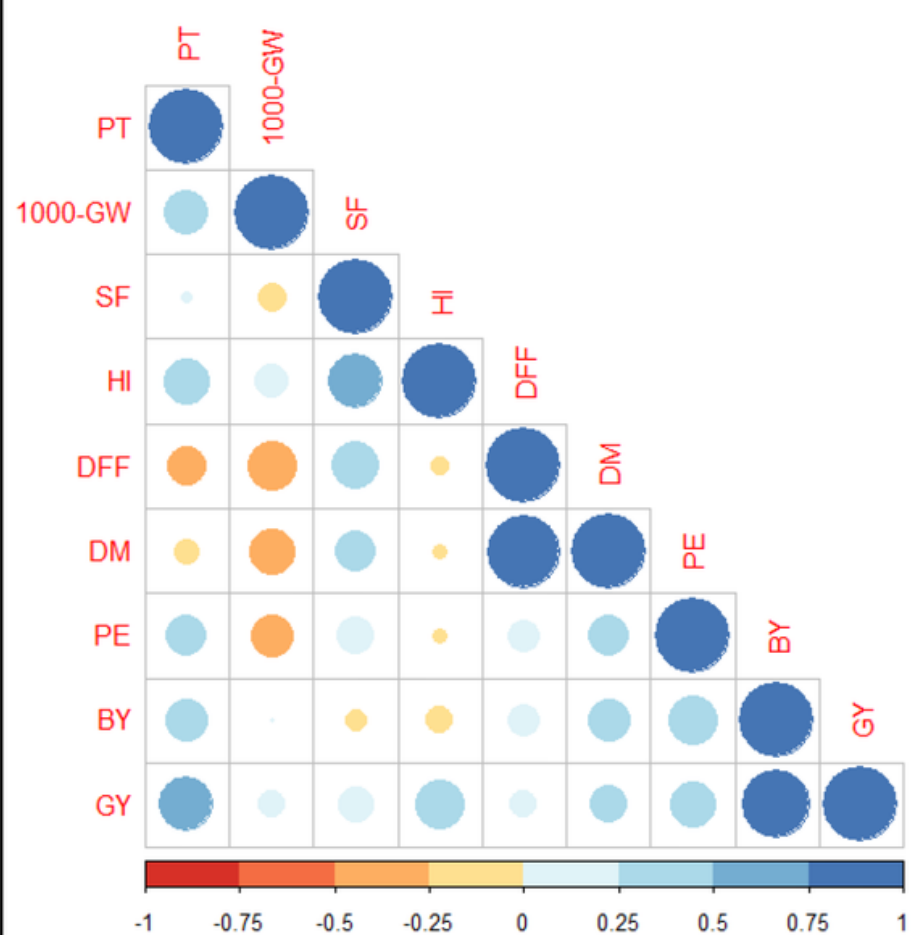

(a)

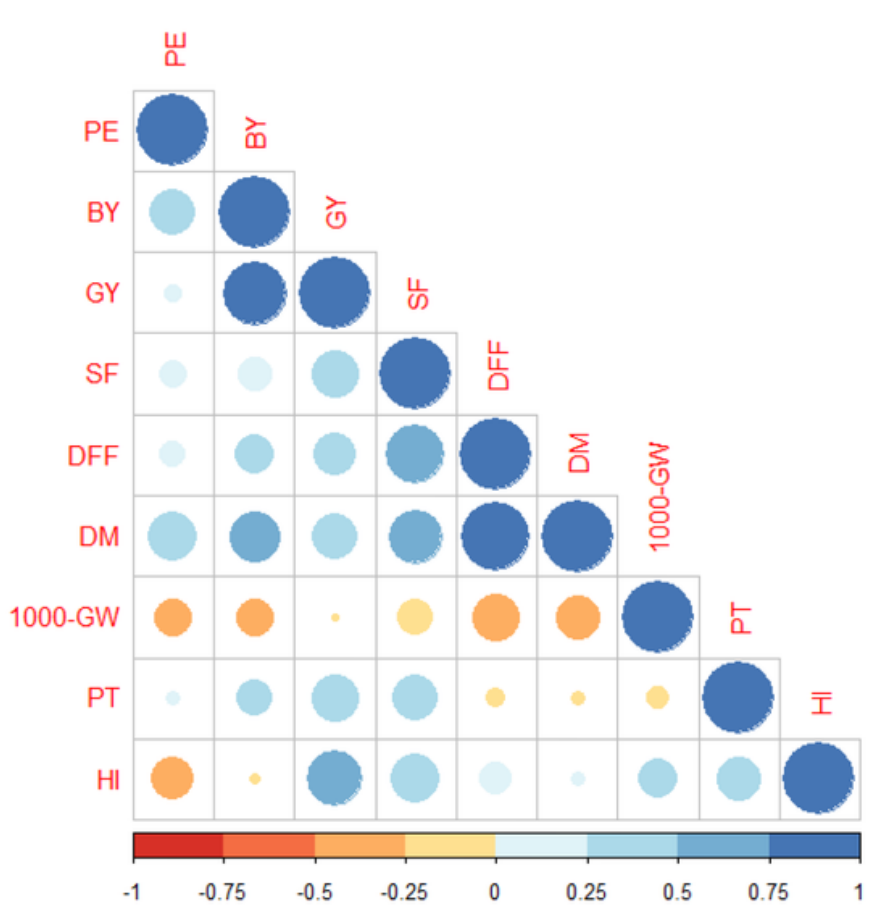

(b)

Figure 5

a Plot of correlation between each of the nine phenotypic traits under aerobic condition; b. Plot of correlation between each of the nine phenotypic traits under RMS condition; Days to 50\% flowering (DFF), Days to maturity (DM), Productive tillers per plant (PT), Panicle exertion (cm) (PE), Spikelet fertility (\%) (SF), 1000-grain weight (g) (1000-GW), Biomass yield (kg/ha) (BM), Harvest index (HI) and Grain yield (kg/ha) (GY). Blue color indicates positive correlation and red color indicates negative correlation among different traits, with color intensity variance depicting the strength of correlation.

\section{Supplementary Files}

This is a list of supplementary files associated with this preprint. Click to download.

- Tables1.docx

- Tables2.docx

- TableS3.docx 